International Journal of Health Sciences
Available online at www.sciencescholar.us
Vol. 5 No. 3, December 2021, pages: $276-285$
e-ISSN: 2550-696X, p-ISSN: $2550-6978$
https://doi.org/10.53730/ijhs.v5n3.1503

\title{
Psychological Features of Post-COVID Syndrome Course
}

\author{
(D) cosshank \\ Vitalii Y. Bocheliuk ${ }^{\text {a }}$ Liana V. Spytska ${ }^{\text {b }}$, Olena V. Mamicheva ${ }^{c}$, Mykyta S. Panov $^{d}$,
Viktoria V. Kordonets \\ Manuscript submitted: 27 May 2021, Manuscript revised: 18 August 2021, Accepted for publication: 11 September 2021
}

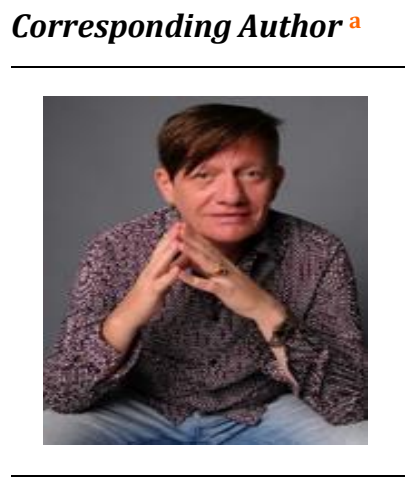

Keywords

anxiety level;

coronavirus;

psychoemotional

disorders;

symptoms;

temperament;

\begin{abstract}
Recently, the so-called post-COVID syndrome has been making itself felt more and more. Given the fact that diseases associated with coronavirus have acquired the character of an epidemic since the end of 2019, the features of the impact of this virus on the bodies of modern people have not yet been studied at all. The study analyses the features of the post-COVID syndrome. The authors investigated the features of the course of "long COVID" in people with various psychological characteristics - anxiety, temperament, empathy, personality type. The study contains certain suggestions for providing psychological assistance to people with a predisposition to coronavirus neuroses. The purpose of the study is to identify the features of the course of the post-COVID syndrome in a different age, gender, socially stratified categories of the population; to analyze the influence of psychological characteristics of the personality on the specifics of manifestations of various symptoms of the postCOVID state. As a result of the study, it was identified that timely prevention of post-COVID syndrome should take place by developing special tests to determine the tendency to neurotic manifestations and psychoemotional disorders. It is necessary to create a methodology for getting out of the "long COVID" as soon as possible.
\end{abstract}

International Journal of Health Sciences (C) 2021. This is an open access article under the CC BY-NC-ND license (https://creativecommons.org/licenses/by-nc-nd/4.0/).

\section{Contents}

Abstract

a Zaporizhzhia Polytechnic National University, Zaporizhzhia, Ukraine

b Volodymyr Dahl East Ukrainian National University, Severodonetsk, Ukraine

c Donbas State Pedagogical University, Sloviansk, Ukraine

d Khortytsia National Educational Rehabilitation Academy, Khortytsia, Ukraine

e Donbas State Pedagogical University, Sloviansk, Ukraine 
2 Signs of post-COVID syndrome.

3 Factors affecting the severity and duration of post-COVID syndrome.

4 Conclusion

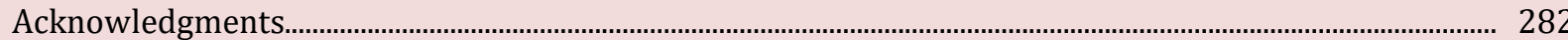

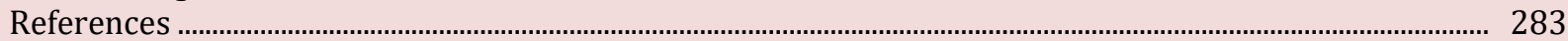

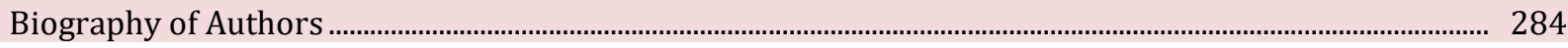

\section{Introduction}

During the existence on the planet Earth of such a biological species as Homo sapiens, more than 500 million human individuals, according to experts, died from various kinds of pandemics. The most terrible epidemic for humanity was the bubonic plague, which, according to various estimates, only in the Middle Ages "took" from 60 to $85 \%$ of the population. Of course, modern medicine can overcome severe infectious diseases, but despite this, the coronavirus disease (COVID-19) caused more than 1 million deaths during the year alone (Solovieva et al., 2020). COVID-19 is a new viral infection that has several features, such as rapid spread, high mortality, and considerable social and economic consequences. COVID-19 destroys people's habitual way of life. Thus, in addition to a large number of deaths, the pandemic has provided the world's population with considerable economic, physical, and psychoemotional problems.

Recently, the so-called post-COVID syndrome has been making itself felt more and more, and leading psychologists and psychotherapists are involved in overcoming it in addition to scientists and doctors. Given the fact that diseases associated with coronavirus have acquired the character of an epidemic since the end of 2019, the features of the reaction of the human psyche to the disease of its body have not yet been studied. The study examines the problem of the influence of psychological characteristics of the individual on the symptoms, severity, and duration of manifestations of "long COVID" in people depending on gender, age, social status, but the main attention is focused on their psychological qualities (Pavli et al., 2021; Afrin et al., 2020). The purpose of the study is to identify the features of the course of the post-COVID syndrome in different ages, gender, socially stratified categories of the population; to analyze the influence of psychological characteristics of the personality (temperament, psychological type, level of anxiety) on the specifics of manifestations of various symptoms of the post-COVID state.

The problem of psychoemotional disorders in patients with coronavirus infection, as well as those who have already had COVID-19, was raised by Chinese psychologists Wang et al. (2020), who regularly addressed this issue in the publications of the journal "Brain, Behaviour and Immunity". Their co-authored paper "A longitudinal study on the mental health of the general population during the COVID-19 epidemic in China" focuses on the mental responses of patients of different populations to the news of their diagnosis, the course of the disease, and the condition after receiving negative tests for the virus after treatment. Other Chinese psychologists and psychiatrists - Bo et al. (2021); Huang \& Zhao (2020), wrote about the features of the course of COVID disease in patients with chronic neurotic disorders, about various kinds of post-traumatic stress disorders (PTSD) in COVID-19 disease in the most vulnerable segments of the population.

European and American doctors in their research also pay attention to the psychological features of the course of "long COVID" (Mair, 2020; Readfearn, 2020; Romero-Sanchez et al., 2020). A fairly large-scale work was published in the United States by doctors of Medical Sciences Tucker \& Czapla (2020), in which they, among other issues related to the COVID-19 pandemic, addressed post-COVID stress disorder and predicted that the named psychological disorder would be one of the consequences of the global pandemic. At the same time, in Ukrainian psychology, the problem of psychological features of the course of the post-COVID syndrome is poorly covered in the scientific literature. Recent publications include studies of Shtohrin (2020); Doroshenko (2020), as well as authors whose works were included in the large collection "Psychology and pedagogy in response to the COVID-19 pandemic" edited by Kremen (2020). The tribute should be paid to Ukrainian journalists, publicists, and bloggers who conduct their independent research on the symptoms of the post-COVID syndrome, the impact of quarantine and post-quarantine periods on the population's perception of news about COVID-19 in the information space, pay attention to the psychoemotional atmosphere in the country (Kovalchuk, 2020; Bida, 2020).

Bocheliuk, V. Y., Spytska, L. V., Mamicheva, O. V., Panov, M. S., \& Kordonets, V. V. (2021). Psychological features of post-COVID syndrome course. International Journal of Health Sciences, 5(3), 276-285. https://doi.org/10.53730/ijhs.v5n3.1503 


\section{Signs of post-COVID syndrome}

Provide S. Mair (2020), a researcher at the University of Surrey, noted in one of his recent studies: "The COVID-19 pandemic may cause changes that will make people talk about the world 'before' and 'after' - just like the terrorist attacks in the United States on September 11, 2001, and the global financial crisis of 2008. It will be possible to learn about certain consequences only later, and some phenomena are an obvious reality today". The infection often (or even in most cases) divides the lives of specific people into "before" and "after", affecting their psychoemotional state. This was noticed in one of his recent speeches by the Director-General of the World Health Organization (WHO), Mr. Tedros Adhanom Ghebreyesus, who noted that the pandemic has affected the mental health of millions of people (Shtohrin, 2020). Today, most people who have personally suffered from coronavirus experience acute stress disorder. Many people will experience post-traumatic stress disorder. But there are certain categories of people who have acquired psychological trauma from what they have experienced in the form of prolonged anxiety disorders, depressive episodes, neurotic disorders, in the form of personal deformities, and so on. Thus, touching upon the topic of mental disorders provoked by the COVID-19 pandemic, "coronavirus" or "post-COVID" syndrome can be mentioned.

Let us focus on the characteristic features of the psychological and mental state of people who are ill or have suffered an acute phase of diseases associated with coronavirus infection, that is the so-called postCOVID syndrome. Specialists identify Post-COVID-19 syndrome, also known as Long COVID, as the effects of COVID-19 infection, in which a certain number of people who have mostly already had this infection suffer from long-term symptoms. Experts do not exactly name the duration of this syndrome. This refers to a period of up to 12 weeks, and in 2.3\% of cases - even longer (Nabavi, 2020). American and English doctors believe that the cause of post-COVID mental disorders is not a specific, time-localized trauma, but long-term neurotic experiences that go beyond the usual experience, fear of death, change in life plans, instability and uncertainty of the future after an illness, fear of recontamination, as well as a large amount of unconstructive disturbing information in the media (mass media) and Internet sources. Various kinds of phobias against the background of COVID-19 equally affect both well-known, financially secure people, and those who are commonly called socially vulnerable (Readfearn, 2020; Doroshenko, 2020).

Ukrainian infectious disease doctor 0. Hetman believes: "Post-COVID syndrome is not a direct impact of the virus. If all the basic blood parameters are normal, then post-COVID pain will be associated with exhaustion of the body, but not with the viral process" (Kovalchuk, 2020). Many doctors still claim that the coronavirus can "affect the vessels of the central nervous system, so people have depressive and suicidal thoughts" (Doroshenko, 2020). Even today, when almost a year and a half has passed since the spread of infection on the European continent, many studies have appeared related to the features of the transfer of both the disease itself and post-COVID syndrome. Referring to this syndrome in general, now any ordinary citizen can find out about it by finding information on the Internet or even getting an online consultation with doctors. As noted at the beginning of the study, there are not enough real major scientific publications on this topic. Ukrainian journalist, the special correspondent of the Hromadske studio Bida (2020), interviewed Olha (31 years old) and Tatiana (42 years old) from Kyiv, who had a COVID infection.

Olga, who got ill in April 2020, received a test with a negative result for coronavirus in June. But even on the eve of the new year, 2021, Olha still did not feel healthy: the temperature "jumped" during the day, weakness was felt, reactive arthritis remained - leg joints swelled, eyes periodically inflamed, and body aches appeared. Tatiana suffered from COVID in a mild form: she lost the sense of smell, cough, aches, incredible fatigue occurred; the temperature did not rise above normal. The woman got ill in the middle of October 2020 and received a negative test three weeks later. After the "recovery", Tatiana's temperature regularly rises to $37.6^{\circ} \mathrm{C}$, an old injury has worsened, her head and eyes hurt, and the woman is unable to be at work due to incredible fatigue after $1 \mathrm{pm}$. Thus, medical experts have identified that people with post-COVID syndrome most often complain of fatigue, cough, chest and joint pain, headache, shortness of breath. An increase in temperature to $38^{\circ} \mathrm{C}$, exacerbation of chronic diseases is also characteristic. Among the symptoms of the postCOVID syndrome, gastrointestinal disorders, metabolic disorders, "COVID fingers" syndrome are recorded the toes swell and become covered with a rash. In total, medical researchers recorded almost 70 symptoms of post-COVID manifestation (Readfearn, 2020; Kremen, 2020).

However, in half of the cases with people who went to doctors with such symptoms, the latter cannot find changes in the body parameters of post-COVID patients. Ukrainian doctor, Candidate of Medicine O. Hetman, 
professor of primary medicine from Oxford T. Greenhall call this phenomenon "psychosomatic syndrome": due to the pandemic, the level of anxiety and fear in people is increased, so often both the acute phase of COVID-disease and post-COVID syndrome are accompanied by mental health disorders (mainly panic attacks, depression, bad mood) (Kovalchuk, 2020; Widana et al., 2021). By all indicators, the person has already recovered, but the stress suffered from the news of the diagnosis of COVID-19, fear of infecting others, hospitalization, characteristic COVID symptoms, being in intensive care, as well as possible economic difficulties and loss of income, can lead to long-term depressive states. T. Greenhall believes that women, the elderly, and those who have had a severely acute phase of the disease are more susceptible to panic attacks, prolonged depression, and negative moods. O. Hetman estimated that among people aged 18-36 years, the post-COVID psychosomatic syndrome was registered in 26\% of cases, among people aged 35-49-32\%, and in the group "over 50" - up to 47\% (Kovalchuk, 2020). Some experts disagree with such conclusions, assuring: middle-aged men are more susceptible to serious depressive states bordering on suicidal mood; patients who have suffered a short and mild acute phase of the disease are often "stuck" for a long time on a post-COVID violation of their mental state; psychosomatic and psychoemotional manifestations of Long COVID do not depend on the age, gender, or social status of the person. More accurate markers of this condition are temperament, psychological type, level of anxiety of the individual, and other psychological personality traits (Kremen, 2020; Romero-Sánchez et al., 2020).

\section{Factors affecting the severity and duration of post-COVID syndrome}

The authors of this study decided to give statistics that they received from the media, Internet sources, as well as through interviews and psychological testing of people for whom the disease and further condition, including mental, is not a secret, and who agreed to share their experience of dealing with post-COVID syndrome. Referring to cases of suicides that occurred in Ukraine and the world as a result of coronavirus disease and post-COVID syndrome, the following picture can be observed. During the period from the end of September 2020 to the beginning of February 2021, five cases of suicide were officially recorded on the territory of Ukraine against the background of a long course of COVID-19: men - 68 and 43 years old (September), a woman - 60 years old and a man - 68 years old (October), a man - 39 years old (February 3, 2021) (Di Blasi et al., 2021; Lima et al., 2020). Special attention should be paid to the latest case when a cheerful 39-year-old tax inspector cut his carotid artery in front of the medical staff. Doctors noted that the deceased had every chance to recover, although the pneumonia was severe and he "had to overcome the postCOVID syndrome".

Approximately the same picture is shown by studies of Chinese doctors. $85 \%$ of COVID suicides are male; the average age of those who committed suicide is 53 years; $65 \%$ of suicides had a severe form of COVID (Bo et al., 2021). Moreover, according to the results of a large web survey in the United States, suicidal thoughts were significantly higher for young respondents aged 18 to 24 years (25.5\%), minority groups (Hispanics, 18.6\%; Dark-skinned people, 15.1\%), those who, while ill themselves, cared for more seriously ill (30.7\%), and junior medical staff (21.7\%) (Simms et al., 2020). Surveys at a city hospital in a small city in eastern Ukraine have shown that older men suffer more from severe depression and severe neurotic disorders, regardless of their position on the "social ladder", who have suffered from severe coronavirus infections or were considered moderate patients. At the same time, women aged 33-50 years, mainly from low-income segments of the population, are more susceptible to prolonged anxiety, especially in the manifestation of hypochondria and post-traumatic stress disorders.

In general, people who had COVID-19 complained of constant anxiety - 44\% of respondents, insomnia $40 \%$ of patients, moderate depression $-36 \%$. Symptoms of post-traumatic stress disorder were found in $32 \%$ of respondents. As a result of the study, it was necessary to state the fact that the severity and duration of the post-COVID syndrome in people who continue to get sick and those who have recovered from coronavirus infection are affected by the level of empathy, the level of anxiety, the level of intelligence, the psychological type of a person, temperament (Moghanibashi-Mansourieh, 2020; Cao et al., 2020). People with a high level of empathy as a humanistic component of spirituality, and the ability to empathize, either passed the state of the post-COVID syndrome or soon got rid of it (Hussin et al., 2021; Ningsih et al., 2021).

Bocheliuk, V. Y., Spytska, L. V., Mamicheva, O. V., Panov, M. S., \& Kordonets, V. V. (2021). Psychological features of post-COVID syndrome course. International Journal of Health Sciences, 5(3), 276-285.

https://doi.org/10.53730/ijhs.v5n3.1503 
For example, Svitlana O., 57 years old, introvert, phlegmatic, on the F.U. Taylor scale (Kokun et al., 2011), has an average level with a tendency to high levels of anxiety, according to the diagnosis of the level of empathic abilities by V. Boyko (Tsyhulska, 2013), - also a high level. She suffered from moderate COVID (pleurisy, prolonged cough, conjunctivitis, weakness, temperature changes up to $37.8^{\circ} \mathrm{C}$ ), says: "I did not experience a single minute of fear of death, depression from illness and isolation. I called my family three times a day to find out how they were feeling. Of course, a prolonged cough was exhausting, not all the prescribed medications helped, but the thought that my family and friends were healthy gave me strength and faith that my illness was about to end... Rest, herbs, vitamins, prayer, communication with my family and friends online... One day the cough stopped, a little later - conjunctivitis, and a week later the isolation regime. For some reason, I am not afraid of recontamination... But I am worried about my children and grandchildren". Maryna T., 26 years old, had a mild form of COVID-19 (loss of smell, taste, runny nose, weakness), an introvert, according to the diagnostics of the level of empathic abilities by V. Boyko has a high level, on the Taylor scale has a high level of anxiety, reports: "I did not feel well for the first week. I was nervous, had bad dreams... I was not much worried about myself, but I was worried about my mother and my boyfriend Dima, with whom I was in close contact (Xiong et al., 2020; Moccia et al., 2020). When I found out that their tests were negative, I completely calmed down. Three weeks after the infection was detected, I, now having a negative test and feeling normal, started working. Everything is OK!".

A psychological state similar to that of Svitlana and Maryna was experienced by $45 \%$ of respondents (45 people), of which 35 people were women with a high level of empathy, the rest, 10 people, were the same men. Among the recipients were also people for whom COVID-infection was complicated (4 people). Among the hundred people surveyed who had COVID-19, 54 were introverts, and 46 were extroverts. Among introverts, 10 people $(18.5 \%$ of the total number of introverts surveyed) have long-term complicated symptoms of the post-COVID syndrome, while among extroverts - 3 (6.5\%): two women over 50 and a 43 year-old man. Spanish doctors have established that more than half of the 841 patients hospitalized with COVID-19 had neurological symptoms. Out off, these, non-specific neurological symptoms were detected, as well as disorders of consciousness (19.6\%), mainly in elderly patients, those suffering from severe COVID-19 disease, and bright introverts; myopathy (3.1\%); dysautonomia (2.5\%); and other less frequent symptoms. Neuropsychiatric symptoms were reported in $19.9 \%$ of these patients, including insomnia, anxiety, depression, and psychosis; they were not associated with disease severity and did not depend much on the individual's belonging to intro- or extraversion (Romero-Sánchez et al., 2020).

Chinese health workers express their point of view: "extroverts who are prone to depression against the background of COVID-19 in percentage terms are no less than intros. But introverts are more likely to have prolonged depressions, and extroverts are more likely to have seizures, but more acute - especially in choleric people" (Huang \& Zhao, 2020). To investigate how exactly the severity of the post-COVID syndrome and its duration affected people with different dynamics of mental activity (with different temperaments), the authors of this paper had to expand the circle of people for their research and study 168 people aged 25 to 65 years who were discharged from different hospitals after coronavirus infection and had signs of various kinds of post-COVID disorders. In all recipients, it was possible to establish a predominant temperament using Eysenck's tests without any problems (Simms et al., 2020). In recent years, such a factor as the prevailing dynamics of mental activity and taking into account the temperament of a person under various circumstances of his life is no longer as popular as a few decades ago. But it cannot be entirely dismissed. The results of the research become quite clear considering Table 1.

Table 1

Dependence of the course of post-COVID syndrome on the dynamics of mental activity of the individual

\begin{tabular}{|c|c|c|c|c|}
\hline \multirow{2}{*}{$\begin{array}{l}\text { Manifestations / Number of respondents } \\
\text { post-COVID syndrome }\end{array}$} & \multicolumn{4}{|c|}{ T E M P E R A M E N T } \\
\hline & choleric & sanguine & phlegmatic & melancholic \\
\hline $\begin{array}{l}\text { The number of recipients who have signs of post-COVID } \\
\text { syndrome - } 168\end{array}$ & 42 & 38 & 30 & 58 \\
\hline Suicidal moods and suicide attempts & 1 & - & - & 2 \\
\hline Personal deformities & 4 & 2 & 3 & 1 \\
\hline Serious and moderate neurotic disorders & 39 & 32 & 25 & 58 \\
\hline
\end{tabular}


- panic attacks

- social phobias

- generalised anxiety disorder

- mixed anxiety and depressive disorder

- compulsive ideas

- auditory or visual hallucinations

- delayed physical responses (insomnia, somatisation, eating disorders, cough, fever, immune disorders, fatigue)

- impaired concentration and attention

- memory impairment

- traumatic memories

- aggressiveness

- irritability

- euphoria

- chronic psychogenic pain, persistent hypochondria

Depressive episodes

Bad mood

The presence of all these manifestations

The presence of more than 10 manifestations

The presence of more than 5 manifestations

$\begin{array}{llll}20 & 7 & 4 & 33 \\ 4 & 1 & 3 & 7 \\ 10 & 10 & 17 & 49 \\ 26 & 16 & 15 & 46 \\ 18 & 8 & 11 & 7 \\ 8 & 14 & 3 & 5 \\ 42 & 38 & 30 & 58\end{array}$

$\begin{array}{llll}42 & 33 & 21 & 58 \\ 30 & 31 & 14 & 36 \\ 14 & 10 & 22 & 57 \\ 36 & 13 & 12 & 9 \\ 42 & 13 & 11 & 10 \\ 10 & 18 & 5 & 5 \\ 11 & 10 & 13 & 39 \\ 26 & 11 & 15 & 32 \\ 40 & 11 & 17 & 44 \\ 10 & 10 & 5 & 20 \\ 12 & 14 & 10 & 24 \\ 20 & 14 & 15 & 14\end{array}$

The duration of the "long COVID" depending on the psychological qualities of the individual is still impossible to determine unambiguously since it is too early to say that those recipients with whom the authors of the paper and other psychologists had to contact have completely got rid of the symptoms of the post-COVID syndrome. For example, panic attacks equally "haunt" both introverts and extroverts, although the latter are more adept at managing their depressed mood and switching attention. Although according to the results of the study, sanguine people are less susceptible to post-COVID neuroses, their duration is almost the same as the duration of similar conditions in choleric and melancholic people (Solé et al., 2021; Song et al., 2021). Thus, a study conducted with a certain number of patients proved that in general, lonely, low-income people, regardless of age and gender, are more prone to severe and moderate neurotic, psychoemotional reactions; introverts; people of melancholic and choleric temperaments; people with a low level of empathic abilities. However, it is too early to give conclusions since on different continents, in different countries, even in neighboring hospitals or hospital wards, there may be considerable differences both in the specifics of postCOVID manifestations and in their duration, and the presence of such symptoms in general.

Thus, the problem of taking into account the psychological characteristics of patients in the treatment of the infection itself, and especially post-COVID syndrome, can become extremely important. Doctors from other countries working with patients with post-COVID syndrome seriously fear that it may be even more dangerous and may become a global problem for humanity (Wang et al., 2020; Tucker \& Czapla, 2020). A. Golamrezanejad, a professor of radiology in Los Angeles, warns: "the syndrome could affect millions of people who have not been hospitalized with COVID-19. And this will burden primary medicine more than the pandemic itself. The medical systems of many countries will have a long time to deal with both the physical and psychological consequences of the coronavirus".

\section{Conclusion}

Thus, according to the overwhelming majority of experts, the post-COVID syndrome is a mental disorder that is a kind of reaction to the COVID-19 pandemic. This disorder has already affected $15 \%$ of the affected population. Nowadays, an acute stress response is increasingly observed against the background of the spread of infection and changes in the usual way of life. The most severe manifestations in their clinical picture are similar to post-traumatic stress disorder. The danger of this syndrome is that it will continue to reduce the

Bocheliuk, V. Y., Spytska, L. V., Mamicheva, O. V., Panov, M. S., \& Kordonets, V. V. (2021). Psychological features of post-COVID syndrome course. International Journal of Health Sciences, 5(3), 276-285.

https://doi.org/10.53730/ijhs.v5n3.1503 
working capacity of the population at a time when it will be so important for the recovery of the economy. As a rule, risk groups are considered to be medical professionals who assist patients with COVID; people who have had a severe form of the disease; people who have lost relatives and friends; those who have suffered considerable financial losses or lost their jobs, and people of specific psychological types.

The issues raised in this paper require further detailed development and research in both theoretical and practical areas. It is time to study the risk groups in more depth, based on the age, gender, personality, and psychological affiliation of people affected by coronavirus infection. Shortly, it will be possible to objectively study the problem of the duration of the post-COVID syndrome in people with different psychological qualities. Other aspects related to the problem of overcoming post-COVID symptoms by different categories of the population, despite the wide interest of researchers in them, require more attention due to the high degree of their relevance.

Acknowledgments

We are grateful to two anonymous reviewers for their valuable comments on the earlier version of this paper. 


\section{References}

Afrin, L. B., Weinstock, L. B., \& Molderings, G. J. (2020). Covid-19 hyperinflammation and post-Covid-19 illness may be rooted in mast cell activation syndrome. International Journal of Infectious Diseases, 100, 327-332. https://doi.org/10.1016/j.ijid.2020.09.016

Bida, O. (2020). Symptoms that are with you for a long time. What is a "long-lasting code" and how to deal with it.

Bo, H. X., Li, W., Yang, Y., Wang, Y., Zhang, Q., Cheung, T., ... \& Xiang, Y. T. (2021). Posttraumatic stress symptoms and attitude toward crisis mental health services among clinically stable patients with COVID19 in China. Psychological medicine, 51(6), 1052-1053.

Cao, W., Fang, Z., Hou, G., Han, M., Xu, X., Dong, J., \& Zheng, J. (2020). The psychological impact of the COVID-19 epidemic on college students in China. Psychiatry research, 287, 112934. https://doi.org/10.1016/j.psychres.2020.112934

Di Blasi, M., Gullo, S., Mancinelli, E., Freda, M. F., Esposito, G., Gelo, O. C. G., ... \& Coco, G. L. (2021). Psychological distress associated with the COVID-19 lockdown: A two-wave network analysis. Journal of affective disorders, 284, 18-26. https://doi.org/10.1016/j.jad.2021.02.016

Doroshenko, K. (2020). World intellectuals on the consequences of the coronavirus pandemic for humanity.

Huang, Y., \& Zhao, N. (2021). Mental health burden for the public affected by the COVID-19 outbreak in China: Who will be the high-risk group?. Psychology, health \& medicine, 26(1), 23-34.

Hussin, D. A., Samah, M. A. A., Suhaimi, A. A., \& Kamarudin, M. K. A. (2021). A study on knowledge, attitude and practice of COVID-19 pandemic among the residents. International Journal of Health Sciences, 5(2), 177188.

Kokun, O. M., Pishko, I. O., Lozinska, N. S., Kopanytsia, O. V., \& Malchazov, O. R. (2011). Collection of methods for diagnosing the psychological readiness of servicemen under the contract to work in peacekeeping units: Methodical manual. Kyiv, Ukrain: NDC GP of the Armed Forces of Ukraine.

Kovalchuk, H. (2020). Healthy but sick. What is postcocious syndrome and how to survive it.

Kremen, V.H. (2020). Psychology and pedagogy in response to the COVID-19 pandemic. Kyiv: TOV "Yurka Lyubchenka".

Lima, C. K. T., de Medeiros Carvalho, P. M., Lima, I. D. A. A. S., de Oliveira Nunes, J. V. A., Saraiva, J. S., de Souza, R. I., ... \& Neto, M. L. R. (2020). The emotional impact of Coronavirus 2019-nCoV (new Coronavirus disease). Psychiatry research, 287, 112915. https://doi.org/10.1016/j.psychres.2020.112915

Mair, S. (2020). What will the world be like after coronavirus? Four possible futures. The Conversation, 30 , 2020.

Moccia, L., Janiri, D., Pepe, M., Dattoli, L., Molinaro, M., De Martin, V., ... \& Di Nicola, M. (2020). Affective temperament, attachment style, and the psychological impact of the COVID-19 outbreak: an early report on the Italian general population. Brain, behavior, and immunity, 87, 75-79. https://doi.org/10.1016/j.bbi.2020.04.048

Moghanibashi-Mansourieh, A. (2020). Assessing the anxiety level of Iranian general population during COVID19 outbreak. Asian journal of psychiatry, 51, 102076. https://doi.org/10.1016/j.ajp.2020.102076

Nabavi, N. (2020). Long covid: How to define it and how to manage it.

Ningsih, S., Ismail, D., \& Indriani, I. (2021). Study protocol: relationship between parenting patterns and diet with nutritional status of toddlers during COVID-19 pandemic. International Journal of Health Sciences, 5(2), 128-134.

Pavli, A., Theodoridou, M., \& Maltezou, H. C. (2021). Post-COVID syndrome: Incidence, clinical spectrum, and challenges for primary healthcare professionals. Archives of Medical Research. https://doi.org/10.1016/j.arcmed.2021.03.010

Readfearn, G. (2020). How did coronavirus start and where did it come from? Was it really Wuhan's animal market. The Guardian, 28.

Romero-Sánchez, C. M., Díaz-Maroto, I., Fernández-Díaz, E., Sánchez-Larsen, Á., Layos-Romero, A., GarcíaGarcía, J., ... \& Segura, T. (2020). Neurologic manifestations in hospitalized patients with COVID-19: the ALBACOVID registry. Neurology, 95(8), e1060-e1070.

Shtohrin, I. (2020). Vyzhyty u karantyn»: yak riatuietsia malyi i serednii biznes i choho ochikuie vid derzhavy [«Survive in quarantine»: how small and medium-sized businesses are saved and what they expect from the state]. Radio svoboda, 2 Apr. p, 6.

Bocheliuk, V. Y., Spytska, L. V., Mamicheva, O. V., Panov, M. S., \& Kordonets, V. V. (2021). Psychological features of post-COVID syndrome course. International Journal of Health Sciences, 5(3), 276-285. https://doi.org/10.53730/ijhs.v5n3.1503 
Simms, A., Fear, N. T., \& Greenberg, N. (2020). The impact of having inadequate safety equipment on mental health. Occupational Medicine, 70(4), 278-281.

Solé, B., Verdolini, N., Amoretti, S., Montejo, L., Rosa, A. R., Hogg, B., ... \& Torrent, C. (2021). Effects of the COVID-19 pandemic and lockdown in Spain: comparison between community controls and patients with a psychiatric disorder. Preliminary results from the BRIS-MHC STUDY. Journal of affective disorders, 281, 1323. https://doi.org/10.1016/j.jad.2020.11.099

Solovieva, N. V., Makarova, E. V., \& Kichuk, I. V. (2020). Koronavirusnyj sindrom": profilaktika psikhotravmy, vyzvannoj COVID-19 ["Coronavirus syndrome": Prevention of phsychotrauma caused by COVID19]. Russkij meditsinskij zhurnal-Russian Medical Journal, (9), 18-22.

Song, W. J., Hui, C. K., Hull, J. H., Birring, S. S., McGarvey, L., Mazzone, S. B., \& Chung, K. F. (2021). Confronting COVID-19-associated cough and the post-COVID syndrome: role of viral neurotropism, neuroinflammation, and neuroimmune responses. The Lancet Respiratory Medicine. https://doi.org/10.1016/S22132600(21)00125-9

Tsyhulska, T. F. (2013). General and applied psychology. Kyiv: Naukova dumka.

Tucker, P., \& Czapla, C. S. (2020). Post-COVID stress disorder: another emerging consequence of the global pandemic. Psychiatric Times.

Widana, I.K., Sumetri, N.W., Sutapa, I.K., Suryasa, W. (2021). Anthropometric measures for better cardiovascular and musculoskeletal health. Computer Applications in Engineering Education, 29(3), 550561. https://doi.org/10.1002/cae.22202

Wang, C., Pan, R., Wan, X., Tan, Y., Xu, L., McIntyre, R. S., ... \& Ho, C. (2020). A longitudinal study on the mental health of general population during the COVID-19 epidemic in China. Brain, behavior, and immunity, 87, 4048. https://doi.org/10.1016/j.bbi.2020.04.028

Xiong, J., Lipsitz, O., Nasri, F., Lui, L. M., Gill, H., Phan, L., ... \& McIntyre, R. S. (2020). Impact of COVID-19 pandemic on mental health in the general population: A systematic review. Journal of affective disorders. https://doi.org/10.1016/j.jad.2020.08.001 


\section{Biography of Authors}

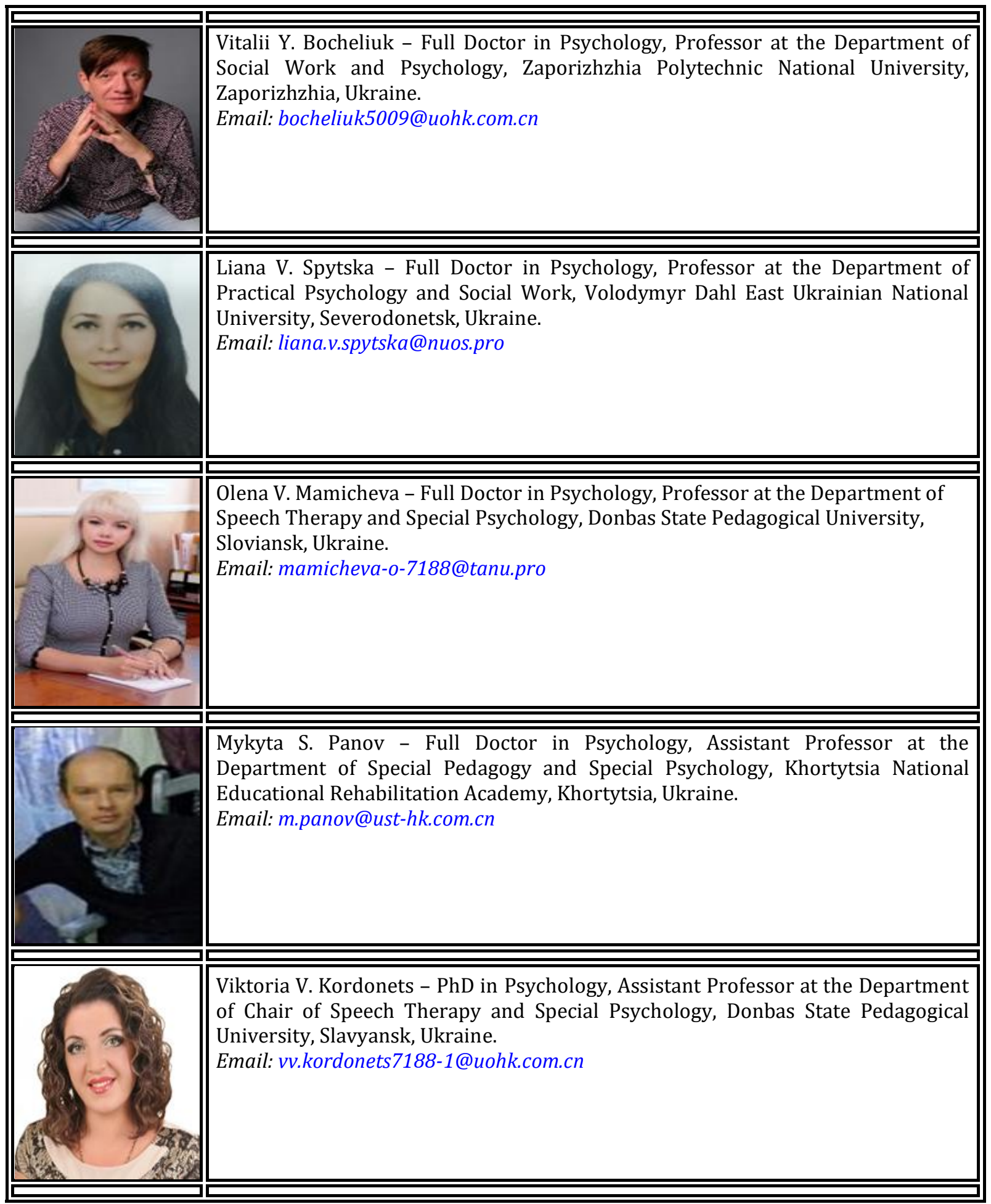

Bocheliuk, V. Y., Spytska, L. V., Mamicheva, O. V., Panov, M. S., \& Kordonets, V. V. (2021). Psychological features of post-COVID syndrome course. International Journal of Health Sciences, 5(3), 276-285. https://doi.org/10.53730/ijhs.v5n3.1503 